\title{
First aid guidelines for Bites and Stings: Educational Approach \& Adaptation
}

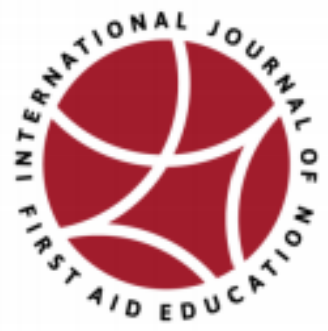

\author{
Panagiotis Ioannidis ${ }^{1}$, William Andre Clucas $^{1}$ \\ ${ }^{1}$ International Committee of the Red Cross
}

\begin{abstract}
Bites and stings can transmit diseases, cause wounds that can become infected, and in some cases, can cause an allergic reaction. Their prevalence across all parts of the world means that they are an important topic to cover in first aid education for most populations and contexts.

Context

The updated First Aid, Resuscitation and Education Guidelines of the International Federation of the Red Cross and Red Crescent (IFRC, 2020) reflect the evidence regarding specific first aid clinical actions and pair the evidence with first aid education. This approach was designed so that users of the Guidelines may easily apply them through adaptation to relevant learner contexts, varying levels of resources and medical care, and with localized implementation strategies.

Educational approach and adaptation

The role of the educator in adapting content to the learner context is crucial for this topic since the variety and level of risk in different countries, and in different localities within countries, is so great. In general, and across all levels of risk and exposure, education needs to focus initially on prevention measures such as covering the body exposed to possible bites and stings; and then on recognition and fast action to manage pain and to reduce the possibility of infection and/or allergic reaction. Visual aids can support learning on this topic to identify reactions which need urgent treatment.

Discussion and conclusions

The immense variety of stinging and biting agents, coupled with the equally great variety of symptoms (in terms of manifestations and severity), makes "Bites and Stings" perhaps one of the most difficult subjects to teach in first aid. Inevitably, there are significant gaps in the evidence base and therefore educators need to retain a principled approach, being clear that they cannot cover all eventualities, but that prevention, fast recognition and treatment can be critical, particularly where there is limited or no access to Emergency Medical Services (EMS.)
\end{abstract}


The International Federation of the Red Cross and Red Crescent (IFRC) updated its 2016 Guidelines (IFRC, 2016) in February 2021 to reflect the evidence regarding specific first aid clinical actions and uniquely paired evidence regarding first aid education. This approach was designed so that users of the Guidelines may easily be able to apply them through adaptation to relevant learner contexts, contextualization to different levels of resources and medical care, and local implementation strategies.

The development of each new guideline and the review of the 2016 version included a new focus on the domains of the Chain of Survival Behaviors (IFRC, 2016) as well as a fresh look through an educational lens across different contexts and the provision of education considerations for each topic. This shift in emphasis occurred in response to calls from developers of curricula and first aid educators from across the Movement (including National Societies and the International Committee of the Red Cross (ICRC)). The process to include these elements was rigorous and consistent and is explained in full in the Guidelines (IFRC, 2020). Topics for inclusion were identified in 2018 using surveys and expert opinion of actors within the Movement. Individuals from 43 countries with clinical and/or educational expertise participated in teams to develop search criteria from existing published literature and grey literature for each research question.

Following a clinical review of evidence, each topic was then considered independently by at least two educational reviewers (including one from a lower resource setting and one from a higher resource setting) who both reviewed existing literature to inform the educational approach to a first aid intervention for that topic. They also drew on their own experience and expertise. Together they then synthesized the insight available and contributed educational aspects to the Chain of Survival Behaviors for that topic. They also provided Education considerations to support the application of the topic in an educational setting. Any conflicts were resolved by an independent Guidelines Steering Committee (GSC) member. Worksheets that described the outcomes of each included work and summary relevance were completed. These were presented for peer review to the GSC.

Each first aid topic is introduced with a key action to be emphasized to learners, a brief explanation of the condition, how common it is and the main population likely to be at risk or affected. The Guidelines that follow are rated by the level of scientific evidence that exists for them. Good practice points are provided where evidence was missing but expert opinion was available based on experience and non-systematic review sources of evidence.

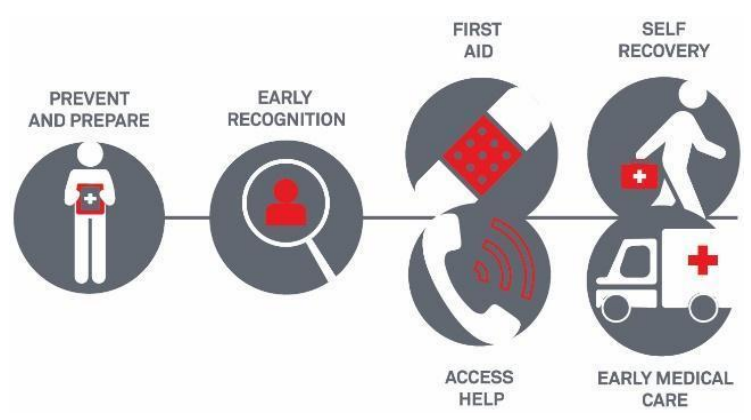

Figure 1: Chain of Survival Behaviors

The Chain of Survival Behaviors is used by the Guideline authors as a tool to emphasize how first aid education does not start and end with a first aid action. The domains of Prevent and Prepare; Early Recognition; First Aid and/ or Access help; and Early Medical Care/ Self-recovery, are fundamental considerations for education depending on the context and learner needs. Each clinical topic covered by the Guidelines includes insight based on evidence and expert opinion on how best to frame an educational intervention using these domains and identifying where educators might best position that learning.

This paper reviews how the 2020 Guidelines incorporated available clinical and educational evidence within the domains of the Chain of Survival Behavior for the first aid trauma topics. It 
then discusses how the educational considerations might be adapted to different learner audiences and their needs.

The trauma topics in the 2020 Guidelines discussed in this paper include stings and bites from insects, other arthropods, snakes, mammals and marine animals. Insect bites rank amongst the major reasons for anaphylaxis (Decker et al., 2008; Helbling et al., 2004). Cases are very common for most parts of the world, with a reported incidence of death from insect sting anaphylaxis at between 40 and 100 per year in the United States alone, although this number is believed to be severely underestimated (Neugut et al., 2001). 'Insect stings and bites are an extremely pertinent topics to tackle during first aid training as recent epidemiological studies on sting anaphylaxis reveal poor management of allergic patients and a general difficulty to predict which individuals are at risk to develop complications after exposure (Bilò \& Bonifazi, 2008). Likewise, with the re-emergence of rabies in many places around the globe (Freuling et al., 2013), and the general danger and frequency of mammal bites (Holmquist \& Elixhauser, 2006) including from humans, dogs, and cats, makes the topic crucial for most first aid curricula.

This paper aims to provide a synthesis and review of the educational considerations and adaptations provided in the 2020 Guidelines for these topics. It also aims to provide additional guidance to educators regarding the methodology and course design, and also propose an approach to structure the content of a "Bites and Stings" session using five distinct groups of cases.

\section{Educational approach}

In this section we have synthesized the education content of four of the 2020 Guidelines first aid topics.

It is important to remember two major considerations when dealing with bites and stings. The first is to deal with the direct effects of the bite or sting, which can range from pain to a complicated anaphylactic reaction. The second important consideration is dealing with the indirect consequences, which are avoidance of actions that would exacerbate the damage and avoiding infection. Prevention goes a long way when discussing these issues, as the majority of their instances are avoidable if the necessary precautions are taken - which makes it an extremely potent element to highlight in the educational approach.

It would be both impossible and impractical to try and list all possible animals that could bite or sting a human, and such an endeavor would go well beyond the scope of this paper. For reasons of convenience below we group together the basic first aid considerations and educational tips for five different groups of incidents. The rationale for the grouping is based on the commonalities found between these cases.

\section{Insect Stings}

Insects often use stings as part of their offence or defense, which are connected to a venomous gland that injects toxins into a wound by piercing. If the stinger is still attached to the person's body, remove it as quickly as possible in a safe manner by gently scraping the sting area with a flat object, such as a bank-type card or butter knife. Generally, using tweezers or any other object that can pierce or press down on the venom bag should be avoided as this may aggravate the symptoms. For honey bee stings, advice from a review not cited in the IFRC 2020 Guidelines suggests that speed of removal outweighs method, and that where a stinger can be pulled out (for example using finger nails) without being broken, this can be a more effective method and one which does not require the use of any specific apparatus (Lee et al, 2020).

The bitten or stung area should be thoroughly cleaned with potable (clean) water and then an antiseptic solution. Since some level of swelling is expected, ensure that any bracelets, rings and other jewelry is removed early to prevent constriction. If no clean water is available, then the first aider can use an antiseptic solution. 
Educators should place particular attention on the early recognition of complications, such as allergic reaction or anaphylaxis (Malić \& Ioannidis, 2021). Likewise, emphasis should be placed on preventive measures, such as avoidance of places swarming with insects, knowledge of specific habits of local insects or snakes (e.g. nocturnal or diurnal,) wearing clothes that cover the extremities, wearing closed shoes, and inspecting food and drink for insects before drinking or eating. This last piece of advice is particularly important as stings to the mouth and neck can often produce complications to the airway. For beekeeping or any other activity where interaction with insects is expected, it is important to use protective equipment. Swarms of stinging insects should be avoided by finding shelter in case of attack.

\section{Arachnid stings}

Scorpions and spiders are the most often encountered species of arachnids that would sting a person. Scorpion and spider envenomation are primarily accidental. Their prevalence across the world is so high and their stings could be so venomous (Chippaux \& Goyffon, 2008) that educators should include them in their curricula for bites and stings. Though most often encountered in the wild (across a huge variety of terrains), venomous spiders are often kept as pets, which makes incidents of envenomation not uncommon even in urban areas (Vetter, 2013). The effects of their sting vary greatly due to the species but can range from persisting pain to multi-system failure and death. It is important that for both spider and scorpion stings, seeking medical assistance is imperative. Delays in seeking medical treatment are associated with higher likelihood of mortality in children and adolescents (Guerra et al., 2008) due to their lower body weights. Assisting medical professionals with recognition of the stinging agent could be helpful.

\section{Other arthropod bites}

Ticks, bedbugs, fleas and mites often attack humans to feed. They don't inject venom (hence the difference from stings), but their bite and saliva's proteins can cause a topical or systemic reaction or even transfer harmful pathogens to the person. Educators should try to help participants recognize the different species by either directly observing them (when their size allows) or recognize the dermatological evidence they leave behind. Ticks should be removed manually using tweezers or forceps, without application of heat, jelly, gasoline or any other solvents. The use of a manufactured tick removal device is preferred when available. Educators should advise when professional care might be required, such as for Lyme's disease. Mosquito bites are extremely common, and most of them are self-limited to a localized reddish bump. Complications might include malaria, West Nile virus, dengue fever, and yellow fever, amongst others - something that is highly related to the prevalence of these diseases in the area. Prevention messages should include the use of repellents, insecticide-treated bed nets while sleeping, and wearing long trousers, shoes and long-sleeved clothes and covering the hands and face in nature or in the presence of insects.

\section{Snake Bites}

The first and foremost consideration for any kind of venomous snake bite (or if it is not known if the snake is venomous) in the first aid guideline is to try and keep the injured limb as immobilized as possible. Movement of the limb pushes the venom further into the body. Pressure immobilization, bandaging, and keeping the limb lower than the heart level may be helpful, contrary to tourniquets that may cause further complications. Suctions, cold compresses, cutting the wound, or rubbing may also make the situation worse. The initial actions after the snake bite are lying down and staying calm, calling for emergency medical support, removing jewelry, and monitoring the vital signs. In case medical care is difficult to access, provide care for the wound to avoid infection. General prevention measures for snake bites contain appropriate clothing (full length trousers, closed shoes etc), being knowledgeable 
of the existence of snakes in the area and avoiding any contact with them.

\section{Mammal Bites}

Dogs, cats, rodents, or other humans' bites could be of concern. The first step in the Chain of Survival Behavior is preventive measures, which, in this case, include avoiding contact with stray and wild animals and the close supervision of children when around them. Acquisition of good knowledge of the local risks (endemicity of diseases in the area, such as rabies, anthrax, hantavirus, bovine, encephalopathy, etc. is advised). Bleeding resulting from the injury should be treated as per current bleeding protocols (direct pressure on the wound). Due to the fact that mouths are thriving in bacteria, any bite from humans or other mammals should be considered contaminated and washed thoroughly with water, saline, and soap or other disinfectant, so as to reduce the microbial load. Vaccination against tetanus (human tetanus immunoglobulin) or rabies should be considered. In case of a large wound, medical advice should be sought so that a decision for closure or non-closure of the wound is made and also the provision of antibiotic treatment.

\section{Aquatic animal injuries}

In case of a jellyfish sting, guidelines suggest immersing the injury in hot water (up to a maximum of $45^{\circ} \mathrm{C} / 113^{\circ} \mathrm{F}$ ) for at least 20 to 30 minutes or application of a heat pack. The person stung should be discouraged from rubbing the site of the injury. In places where deadly jellyfish are known to exist, it is important to remain vigilant and ensure quick access to medical care while closely monitoring the patient's vital signs. Tetanus infection is a possibility, so it is important to consider tetanus immunoglobulin. Topical warmth or pain at the site of the injury are an indication of possible infection that should be monitored and treated when necessary. Avoiding getting into water in the presence of stinging animals (e.g. jellyfish) and protective clothes are the only sure ways of preventing injury. Educators should retrieve information from local sources about the aquatic fauna, as well as the local legislation for the use of medications (like lidocaine or steroid ointments); while vinegar may also be beneficial for certain types of jellyfish sting according to some studies (Ward et al., 2012). The 2020 Guidelines also highlight the importance of avoiding aggravating the injury or risking harm to the first aider, who should use forceps to remove any tentacles which are still on the skin of the person. Sculpins, scorpionfish, echinoderms (like certain types of starfish and urchin) and stingrays' stings can have similar effects and require similar treatment (Burnett et al., 1996). Non-venomous attacks can also take place, such as those from moray eels, piranhas, and sharks; these should be treated with the same considerations as mammal bites.

\section{Table 1}

Summary of Guidelines for Stings and Bites

\begin{tabular}{lccc}
\hline Category & Common agents & $\begin{array}{c}\text { Signs and Symptoms } \\
\text { (early recognition) }\end{array}$ & First Aid guidelines* \\
\hline All & $\begin{array}{c}\text { All patients suffering from } \\
\text { bites and stings should be } \\
\text { closely monitored for signs of } \\
\text { anaphylaxis }\end{array}$ & $\begin{array}{c}\text { Severe symptoms of allergic } \\
\text { reaction possibly including } \\
\text { problems swallowing, } \\
\text { difficulty breathing and/or } \\
\text { swelling of face and neck. }\end{array}$ & $\begin{array}{c}\text { Refer to allergic reaction and } \\
\text { anaphylas section of }\end{array}$ \\
\hline
\end{tabular}


Review

\begin{tabular}{|c|c|c|c|}
\hline Insect Stings & $\begin{array}{l}\text { Bees, Wasps, Ants, } \\
\text { Centipedes, }\end{array}$ & $\begin{array}{c}\text { Pain, allergic reaction and } \\
\text { anaphylaxis }\end{array}$ & $\begin{array}{l}\text { Clean the site of the sting; } \\
\text { Monitor for anaphylaxis }\end{array}$ \\
\hline $\begin{array}{l}\text { Arachnid } \\
\text { stings }\end{array}$ & Scorpions, Spiders & $\begin{array}{l}\text { Pain, visible bite mark, } \\
\text { swelling or discoloration } \\
\text { around bite, shock-like } \\
\text { symptoms, nausea, vomiting }\end{array}$ & $\begin{array}{l}\text { Clean the site of the sting; } \\
\text { Seek medical assistance if } \\
\text { condition worsens, } \\
\text { medication might be } \\
\text { necessary }\end{array}$ \\
\hline $\begin{array}{l}\text { Other } \\
\text { arthropod } \\
\text { bites }\end{array}$ & $\begin{array}{c}\text { Ticks, Mites, Fleas, Bedbugs, } \\
\text { Mosquitos }\end{array}$ & Itching, irritation & $\begin{array}{l}\text { Clean with water and soap; } \\
\text { Don't scratch, don't touch } \\
\text { with dirty fingers, beware of } \\
\text { secondary infection (incl. } \\
\text { vector-borne diseases) }\end{array}$ \\
\hline Snake Bites & Any kind of snake & $\begin{array}{c}\text { Pain, visible bite mark, } \\
\text { swelling or discoloration } \\
\text { around bite, shock-like } \\
\text { symptoms, nausea, vomiting }\end{array}$ & $\begin{array}{l}\text { Don't move the injured } \\
\text { extremity, compression, quick } \\
\text { access to medical care }\end{array}$ \\
\hline Mammal Bites & Dogs, cats, rodents & $\begin{array}{c}\text { Pain, visible bite mark, severe } \\
\text { trauma and bleeding }\end{array}$ & $\begin{array}{l}\text { Trauma care, seek medical } \\
\text { assistance to assess the injury } \\
\text { (possible need for antibiotics) }\end{array}$ \\
\hline $\begin{array}{l}\text { Aquatic animal } \\
\text { injuries }\end{array}$ & $\begin{array}{l}\text { Jellyfish, Sculpins, } \\
\text { Scorpionfish, Stingrays, } \\
\text { Echinoderms (urchins, } \\
\text { crown-of-thorns starfish) }\end{array}$ & $\begin{array}{l}\text { Pain, irritation, itching, skin } \\
\text { discoloration, allergic } \\
\text { reaction and anaphylaxis }\end{array}$ & $\begin{array}{l}\text { Immersion in hot water for at } \\
\text { least } 20 \text { to } 30 \text { minutes } \\
\text { (temperature maximum } 45^{\circ} \mathrm{C} \\
\text { - ie it should feel warm to } \\
\text { touch but not painful), } \\
\text { monitor for anaphylaxis }\end{array}$ \\
\hline
\end{tabular}

Note: * for a detailed list of suggested actions, refer to the International First Aid Guidelines

https://www.globalfirstaidcentre.org/first-aid/

\section{Adaptations}

There is a great variation of biting and stinging agents across the globe and even within different regions of the same country, and the nature of the agent is far from negligible. The risk factors associated with the bite or sting, prevention and follow-up could vary vastly; from the sting of a simple sand fly to the sting of a Physalia physalis (Portuguese man o' war), and from the bite of a pet dog to the bite of Varanus komodoensis (the infamous Comodo dragons), the distance is large in every aspect of the clinical management. This fact by itself makes it very impractical to teach this topic in a uniform way and highlights the great importance of adaptation of the educational content. This adaptation needs to take place at several different levels explained below.

In principle, an often overlooked first level of adaptation happens by assessing the overall risk of the participants to the danger of stings and bites, so that time invested -as part of the overall time of the training- in learning and practicing first aid 
for this topic is analogous to the risk exposure. For example, a first aid training in a European urban center is less likely to need to focus on this topic due to the much lower risk levels compared to the approach of the same topic in a rural area in the tropics where contact with insects is much more common.

In order to provide accurate messages and guide the participants through the chain of care, it is very important to have a clear understanding of the availability of local EMS and also the expected delay in their response. In case the local EMS do not have in their scope of practice drug administration, e.g. the use of adrenaline for anaphylaxis, which is the gold standard (Ring et al., 2018), or the fact that due to geographical limitations EMS cannot be expected to arrive within a short timeframe; in both cases the EMS will be of limited benefit in an acute emergency. If this is the case, it might be better to consider equipping a local first aid kit with autoinjectors or adrenalin vials - or even antihistamines or corticosteroids - to be used by a local healthcare professional with adequate training. Also, given the lack of professional care, instructions for early identification of secondary infection is more important to take place.

Educators should also make sure to adapt the messaging to the age and occupation of the audience, as both play a major factor. Young children in rural settings are much more exposed to insects as compared to adults in urban settings. They are not only disproportionately exposed, but they are also more likely to be stung or bitten without managing to identify the agent, and often the effects are more dangerous. Focus should be given to prevention measures, such as covering the lower parts of the body (full length trousers/pants) and the use of closed shoes, when these are available or protective diving gear when under water. Equally so, certain occupations expose people to additional risk either due to geographical factors (e.g. working in heavy vegetation or close to insects, local distribution of biting/stinging agents), time-related factors (e.g. working during dusk or dawn or at night), or work-related specificities (e.g. parts of body exposed during work, working with animals/beekeeping, scuba diving).

Visual aids can be of immense support in learning and retaining information regarding the topic. Many people, especially those living in rural areas, will be able to recognize the simple dermatological manifestations that follow the most common stings (such as mosquito or bed bug). This will not necessarily be true for more complicated cases or rarer manifestations. Learners can be helped to identify and memorize the classic Lyme disease rash by being shown it in a photo. The patterns of bedbug bites can be shown in comparison to the patterns of flea bites. Some species of spiders, chiggers and scabies also have characteristic marks. Similarly do several species of ants, which cause big nuisance to rural communities. Educators should be careful to use visual aids which show such marks on skin of the same color as the learners and those they will be helping, as the look of the marks can vary according to skin color. Visual aids are also helpful to help identify the biting or stinging agent, with which the patient could be very unfamiliar (e.g. travelers to foreign countries). This is also good material to support an interactive session, where the participants are asked to identify either agents or the effects of the stings or bites. Finally, the use of videos could greatly help participants understand how to properly perform specific skills like sting removal or the use of manufactured tick removal device or tweezers to effectively remove a tick.

\section{Discussion}

One could argue that the topic of stings and bites largely resembles that of the Neglected Tropical Diseases (NTDs) - a term used for a diverse group of tropical infections caused by a variety of pathogens common in low income countries (Hotez et al, 2020). Reliable data on this topic is generally lacking as stings and bites are often 
underreported as they happen in sparsely populated areas with little public health and medical infrastructure, and where there are non-existent data collection mechanisms. At the same time, there is lots of anecdotal evidence that this is a field of first aid laden with misbeliefs, traditional approaches of unreliable efficacy and big costs, or even harmful misconceptions (González \& Vallejo, 2013; Omara, 2020). Without outright discrediting the variety of traditional practices around the world, it is important to emphasize the need for research, so that practices are informed based on solid evidence.

Taking time to dispel myths can also be a very practical tool in the educators' armory, especially for this particular topic. A "myth-buster" session gives room for some welcome interactivity, where the trainer can ask the participants if they agree or disagree with specific statements (e.g. "Should you suck the blood out of a snakebite?", "Should you urinate on a jellyfish sting?", etc.), and then summarize the rationale for the answer. Clarifications on the indications and contraindications of certain medications, such as the use of antihistamines can also be part of such a session, so that people understand the limits of their use (Winbery \& Lieberman, 2002). This can work very effectively as a final recap session.

It is worthwhile for the educator to assess the likelihood that people who have been strung will have been able to seek medical advice. In some rural, remote, conflict affected or low resource settings it will be very difficult for people to access healthcare. In these cases, the educator should be sure to discuss secondary or delayed reaction like infection or disease - which may occur days to weeks after the event.

Moreover, choosing content carefully will also allow time and space to provide more practical advice, which is very important. For example, in many countries, there are specific hotlines to give support for poisoning, which also could provide support with venomous stings. These hotline numbers, together with any emergency numbers which exist in the area and their proper use should be part of the training's discussion. Another suggestion is asking for people to share information about known allergies or sensitivities with their kin/friends, who might be the ones needing to provide first aid in case themselves become incapacitated. An often-forgotten piece of advice that needs to be highlighted is that all dermatological manifestations of bites and stings (i.e. blisters, rashes, bumps, welts, pimples, or hives) should not be scratched, or (ideally) touched with dirty hands to avoid infection.

There are some insect bites that are not mentioned by name in the 2020 Guidelines but contribute disproportionately to the global morbidity and mortality. For example, African trypanosomiasis and Chagas disease are still major disruptions in sub-Saharan and Latin American communities (Kennedy, 2019; Pérez-Molina \& Molina, 2018). Such pathologies are often difficult to tackle exactly because the bite that caused them is non-specific and often becomes disregarded and is often not followed up with adequate investigation. Others, like malaria and dengue, are mentioned indeed, but their great impact on global morbidity is so high that investing time in proper prevention and treatment should be considered with practical sessions on the use of insecticide-treated nets (ITNs) and other prevention measures (Kebede et al., 2020; Wen et al., 2016). The educator should try to raise awareness of the issue when access to such information is not available. This way the first aid training also acts as a form of essential health promotion and forms a stronger link with the rest of the health system, and a smoother transition in the continuum of care.

One final, but often overlooked dimension: however unfortunate they can be, bites and stings are just part of the natural fact that humans are sharing this planet with other animals. This peculiar symbiotic relationship of humans and other animals has often been seen as categorically antagonistic, and there are many cases where 
preventive measures had been so brutal that enormous harm was done to the local fauna and flora. It is the role of the modern educator to bring some environmental sensibility in the approach of this topic. Good prevention is important to be emphasized, but there will always be a certain level of risk when in nature and around animals. Some animals might be more dangerous than others, but they still form an important part of the ecosystem in which they live. Hence, prevention measures should strive to be the least damaging to the environment and animals as possible.

\section{Conclusion}

The immense variety of stinging and biting agents, coupled with the equally great variety of symptoms (in terms of manifestations and severity), makes "Bites and Stings" perhaps one of the most difficult subjects to teach in first aid. Messages are by nature much more "generic" and educators often need to resort to the "depending on the situation", so it is important that trainees retain a principled approach on the subject. Adding to the complexity of the issue is the fact that often these incidents happen in places that are remote and inaccessible, with professional emergency medical care rarely being an option (e.g. while diving, hiking, or in countries with limited resources). Hence, the role of the educator becomes much more crucial - not only at reciting a known formula (which is often the case in first aid training), but making considerable efforts at adapting the content to the context. Summing up, the main messages common for all cases in this topic are: treating the injury site, monitoring for anaphylaxis and severe systemic reactions, supporting the airway, breathing and circulation in case of complications, seeking higher-level medical care when needed, and preventing secondary infections.

\section{Acknowledgements}

We wish to thank the reviewers, writers and editors that were involved in the development of the 2020 Guidelines.

\section{Conflict of Interests}

No conflict of interest exists for any of the authors. The authors were content contributors to the 2020 International first aid, resuscitation, and education guidelines.

\section{Corresponding Author}

Dr Panagiotis Ioannidis, pioannidis@icrc.org

\section{References}

Bilò, B. M., \& Bonifazi, F. (2008). Epidemiology of insect-venom anaphylaxis. Current Opinion in Allergy and Clinical Immunology, 8(4), 330-337. https://doi.org/10.1097/ACl.0b013e32830638c5

Burnett, J. W., Burnett, J., \& Rifkin, J. F. (1996). Venomous and Poisonous Marine Animals: A Medical and Biological Handbook. UNSW Press.

Chippaux, J.-P., \& Goyffon, M. (2008). Epidemiology of scorpionism: A global appraisal. Acta Tropica, 107(2), 71-79. https://doi.org/10.1016/i.actatropica.2008.05.021

Decker, W. W., Campbell, R. L., Manivannan, V., Luke, A., St Sauver, J. L., Weaver, A., Bellolio, M. F., Bergstralh, E. J., Stead, L. G., \& Li, J. T. C. (2008). The etiology and incidence of anaphylaxis in 
Rochester, Minnesota: A report from the Rochester Epidemiology Project. The Journal of Allergy and Clinical Immunology, 122(6), 1161-1165. https://doi.org/10.1016/i.jaci.2008.09.043

Freuling, C. M., Hampson, K., Selhorst, T., Schröder, R., Meslin, F. X., Mettenleiter, T. C., \& Müller, T. (2013). The elimination of fox rabies from Europe: Determinants of success and lessons for the future. Philosophical Transactions of the Royal Society B: Biological Sciences, 368(1623). https://doi.org/10.1098/rstb.2012.0142

González, J. A., \& Vallejo, J. R. (2013). The scorpion in Spanish folk medicine: A review of traditional remedies for stings and its use as a therapeutic resource. Journal of Ethnopharmacology, 146(1), 62-74. https://doi.org/10.1016/i.jep.2012.12.033

Guerra, C. M. N., Carvalho, L. F. A., Colosimo, E. A., \& Freire, H. B. M. (2008). Analysis of variables related to fatal outcomes of scorpion envenomation in children and adolescents in the state of Minas Gerais, Brazil, from 2001 to 2005. Jornal De Pediatria, 84(6), 509-515. https://doi.org/10.2223/JPED.1847

Helbling, A., Hurni, T., Mueller, U. R., \& Pichler, W. J. (2004). Incidence of anaphylaxis with circulatory symptoms: A study over a 3-year period comprising 940,000 inhabitants of the Swiss Canton Bern. Clinical and Experimental Allergy: Journal of the British Society for Allergy and Clinical Immunology, 34(2), 285-290. https://doi.org/10.1111/i.1365-2222.2004.01882.x

Holmquist, L., \& Elixhauser, A. (2006). Emergency Department Visits and Inpatient Stays Involving Dog Bites, 2008: Statistical Brief \#101. In Healthcare Cost and Utilization Project (HCUP) Statistical Briefs. Agency for Healthcare Research and Quality (US). http://www.ncbi.nlm.nih.gov/books/NBK52650/

Hotez, P. J., Aksoy, S., Brindley, P. J., \& Kamhawi, S. (2020). What constitutes a neglected tropical disease?. PLoS neglected tropical diseases, 14(1), e0008001. https://doi.org/10.1371/journal.pntd.0008001

International Federation of Red Cross Red Crescent Societies. (2016). International First Aid and Resuscitation Guidelines 2016.

International Federation of Red Cross Red Crescent Societies. (2020). International First Aid, Resuscitation, and Education Guidelines 2020. https://www.globalfirstaidcentre.org/resource/international-first-aid-resuscitation-and-education-gui delines-2020-2/

Kebede, Y., Abebe, L., Alemayehu, G., Sudhakar, M., \& Birhanu, Z. (2020). School-based social and behavior change communication (SBCC) advances community exposure to malaria messages, acceptance, and preventive practices in Ethiopia: A pre-posttest study. PLOS ONE, 15(6). https://doi.org/10.1371/journal.pone.0235189

Kennedy, P. G. E. (2019). Update on human African trypanosomiasis (sleeping sickness). Journal of Neurology, 266(9), 2334-2337. https://doi.org/10.1007/s00415-019-09425-7

Lee, J. A., Singletary, E., \& Charlton, N. (2020). Methods of honey bee stinger removal: a systematic review of the literature. Cureus, 12(5). https://pubmed.ncbi.nIm.nih.gov/32542133/ 
Malić, Ž., \& Ioannidis, P. (2021). First Aid Guidelines for Allergic Reaction, Seizure and Diabetic Emergency: Educational Approach and Adaptation. International Journal of First Aid Education, 4(1). https://oaks.kent.edu/node/16659

Neugut, A. I., Ghatak, A. T., \& Miller, R. L. (2001). Anaphylaxis in the United States: An Investigation Into Its Epidemiology. Archives of Internal Medicine, 161(1), 15-21. https://doi.org/10.1001/archinte.161.1.15

Omara, T. (2020). Plants Used in Antivenom Therapy in Rural Kenya: Ethnobotany and Future Perspectives. Journal of Toxicology, 2020, 1828521. https://doi.org/10.1155/2020/1828521

Pérez-Molina, J. A., \& Molina, I. (2018). Chagas disease. Lancet (London, England), 391(10115), 82-94. https://doi.org/10.1016/S0140-6736(17)31612-4

Ring, J., Klimek, L., \& Worm, M. (2018). Adrenaline in the Acute Treatment of Anaphylaxis. Deutsches Ärzteblatt International, 115(31-32), 528-534. https://doi.org/10.3238/arztebl.2018.0528

Vetter, R. S. (2013). Spider envenomation in North America. Critical Care Nursing Clinics of North America, 25(2), 205-223. https://doi.org/10.1016/i.ccell.2013.02.006

Ward, N. T., Darracq, M. A., Tomaszewski, C., \& Clark, R. F. (2012). Evidence-based treatment of jellyfish stings in North America and Hawaii. Annals of Emergency Medicine, 60(4), 399-414. https://doi.org/10.1016/i.annemergmed.2012.04.010

Wen, S., Harvard, K. E., Gueye, C. S., Canavati, S. E., Chancellor, A., Ahmed, B.-N., Leaburi, J., Lek, D., Namgay, R., Surya, A., Thakur, G. D., Whittaker, M. A., \& Gosling, R. D. (2016). Targeting populations at higher risk for malaria: A survey of national malaria elimination programmes in the Asia Pacific. Malaria Journal, 15. https://doi.org/10.1186/s12936-016-1319-1

Winbery, S. L., \& Lieberman, P. L. (2002). Histamine and antihistamines in anaphylaxis. Clinical Allergy and Immunology, 17, 287-317. 